\title{
Method for analysis of heavy sulphur compounds using gas chromatography with flame photometric detection
}

\author{
N. Moreira, P. Guedes de Pinho, I. Vasconcelos* \\ Escola Superior de Biotecnologia, Universidade Católica Portuguesa, Rua Dr. António Bernardino de Almeida, Porto 4200-072, Portugal
}

Keywords: Gas chromatography; Flame photometric detection; Sulphur compounds; Wine

\begin{abstract}
A method for analysis of heavy sulphur compounds in wines, based on gas chromatography (GC) with flame photometric detection, is reported. Wine samples preparation includes a dichloromethane liquid-liquid extraction followed by concentration under a nitrogen atmosphere. The extracted fraction was also analysed by GC-mass spectrometry. The method enables high recovery of sulphur compounds in wine and satisfies the requirements of repeatability and sensitivity. Applications of the method to red, white and Port wines are reported.
\end{abstract}

\section{Introduction}

The aroma and flavour of wines are the key attributes for consumers. Sulphur compounds comprise a structurally diverse class of molecules that provides a whole range of characteristic aromatic notes. Generally, the aromatic contributions of these compounds are considered detrimental to wine quality [1-4]. However, new developments in wine research allowed the differentiation of a family of sulphur compounds responsible for a varietal aroma of wines [1].

Volatile sulphur compounds in wines can be classified into two groups: those with a boiling point $<90^{\circ} \mathrm{C}$ (highly volatile compounds) and those with a boiling point $>90^{\circ} \mathrm{C}$ (less volatile or heavy compounds) [2-5]. The highly volatile compounds present in wines are hydrogen sulphide, ethanethiol, methanethiol, carbonyl sulphide and dimethyl sulphide. Most of these compounds are volatilised by simple racking and aeration; however, the appearance of off-flavours linked to sulphur compounds production, during storage of bottled wines, has been reported [6].

The main heavy sulphur compound reported in wine is 3-(methylthio)-1-propanol (methionol), usually found at concentrations above its threshold value, which at-

\footnotetext{
* Corresponding author. Fax: +351-2-25090351.

E-mail address: ivasc@esb.ucp.pt (I. Vasconcelos).
}

tributes a cauliflower aroma [1,2]. Most of the many other heavy sulphur compounds identified in wine, with low detection limits, are usually found at levels below their threshold value; these include 2-mercaptoethanol (poultry-like aroma), 2-methyltetrahydrothiophen-3-one (metallic, natural gas odour), 2-methylthioethanol (french bean aroma), ethyl 3-methylthiopropionate (metallic sulphur aroma), acetic acid-3-(methylthio)propyl ester (cooked potatoes odour), 3-mercapto-1-propanol (sweat odour), dimethyl sulphone (odourless), benzothiazole (rubber odour), 4-methylthiobutanol (chive-garlic aroma) and 3methylthiopropionic acid (butter, rancid odour) [1-5, 7-12].

In order to determine the concentration of sulphur compounds in alcoholic beverages, quantitative methods have been widely described in the literature. The usual technique is gas chromatography (GC) with sulphur-specific detectors: flame photometric detection (FPD), chemiluminescent detection (SCD) and pulsed flame photometric detection (PFPD). In a recent paper, Mestres et al. [5] gives an overview of the analytical methods for sulphur compounds detection in wine using GC; the procedures for sample preparation include liquid-liquid extraction, static and dynamic headspace and solid-phase microextraction. In recent years, headspace solid-phase microextraction (SPME) has been widely used [5,6,12-14]. In general, these methods have a low sensitivity to an increase of ethanol concentration in samples $[13,14]$. 
Due to the importance of sulphur compounds in wine flavour, and their impact as off-flavours and odours, the present paper proposes a sensitive method for rapid and routine determination of these substances. The method allows the recovery and quantification of heavy sulphur compounds by dichloromethane extraction and concentration under a nitrogen flow, followed by a GC analysis with flame photometric detection. Applications of this quantitative method to red, white and Port wines are reported.

\section{Materials and methods}

\section{Materials}

\section{Chemicals}

The sulphur compounds studied were (CAS number in brackets): $S$-(methylthio)acetate [1534-08-3], $S$ (ethylthio)acetate [625-60-5], 2-mercaptoethanol [60-24-2], 2-(methylthio)ethanol [5271-38-5], 2-methyltetrahydrothiophen-3-one [13679-8511], ethyl-3-(methylthio)propionate [13327-56-5], acetic acid-3-(methylthio)propyl ester, 3mercapto-1-propanol [19721-22-3], 3-(methylthio)-1-propanol [505-10-2], cis-2-methyltetrahydrothiophen-3-ol, 3(ethylthio)-1-propanol [18721-61-4], trans-2-methyltetrahydrothiophen-3-ol, 4-(methylthio)-1-butanol [20582-858], benzothiazole [95-16-9], dimethyl sulphone [67-71-0], 3-methylthiopropyl acetate [16630-55-0], 3-methylthiopropionic acid [646-01-5], $N$-3-(methylthiopropyl)acetamide. Cis- and trans-2-methyltetrahydrothiophen-3-ol were synthesised by reduction of 2-methyltetrahydrothiophen-3-one [10]. Acetic acid-3-(methylthio)propyl ester was also produced from the corresponding alcohol by reacting this compound with acetic acid at $50{ }^{\circ} \mathrm{C}$.

The internal standard used for GC analysis was ethyl (methylthio)acetate [4455-13-4]. The standards used in the study had a purity $>98 \%$ and were supplied by SigmaAldrich (Madrid), Fluka (Madrid) and Lancaster (Bischheim, France). Inorganic reagents and solvents were all products of analytical grade, purchased from Merck (Darmstadt, Germany).

\section{Wine samples}

The red, white and Port wines were from different regions in Portugal. The red wines used were produced from grapes of Vitis vinifera of different cultivars (Trincadeira, Alfrocheiro, Aragonês, Touriga Nacional and Touriga Francesa) of the Dão Region (14 samples), from the 1999 vintage. The white wines, from the Vinho Verde Region, were produced from Loureiro, Alvarinho, Trajadura, Azal branco, Pedernã and Avesso cultivars, in the 2000 vintage (12 samples). The Port wines analysed were obtained from grapes of Touriga Nacional, Touriga Francesa, Tinta Barroca, Tinta Cão and Tinta Roriz cultivars of the Douro Region. These are sweet wines produced by the interruption of alcoholic fermentation by addition of grape spirit. The young Port wines used were from the 1999 vintage, with less than 4 years of aging (18 samples), and the old Port wines were of the 'tawny' category, which means that they were blended and barrel-aged for 10, 20, 30 and 40 years (18 samples).

\section{Analytical method \\ Sample preparation}

The internal standard, ethyl (methylthio)acetate, was added to $50 \mathrm{ml}$ of wine or standard solution at $50 \mu \mathrm{gl}^{-1}$. Four grams of sodium sulphate was added to the sample, which was extracted twice with $5 \mathrm{ml}$ portions of dichloromethane for $5 \mathrm{~min}$. Both organic phases were mixed and $2 \mathrm{ml}$ of the solution was concentrated to $1 / 10$ under a nitrogen flow $\left(1-2 \mathrm{ml} \mathrm{min}^{-1}\right)$. The extract $(2 \mu \mathrm{l})$ was injected into the chromatograph. A chromatogram of sulphur compounds in a wine sample is presented in Fig. 1.

\section{GC-FP Danalysis}

Analyses were carried out on a Hewlett-Packard (HP) 5890 gas chromatograph, equipped with a flame photometric detector (FPD), and the HP Chemstation software was used. The FPD used an interference filter set at $394 \mathrm{~nm}$. The chromatograph was equipped with an automatic injection system (HP 6890 series injector). The extract was injected, in the splitless mode for $0.3 \mathrm{~min}$, into a CP-WAX 58 (FFAP)-CB column (Chrompack) of $50 \mathrm{~m} \times 0.32 \mathrm{~mm}$ and $0.2 \mu \mathrm{m}$ phase thickness. The oven temperature programme was from $40^{\circ} \mathrm{C}(10 \mathrm{~min})$ to $220^{\circ} \mathrm{C}(40 \mathrm{~min})$ at $2^{\circ} \mathrm{C} \mathrm{min}^{-1}$. The injector and detector temperatures were $250^{\circ} \mathrm{C}$. The carrier gas used was hydrogen at $1-2 \mathrm{ml} \mathrm{min}^{-1}$. The FPD used hydrogen at $90 \mathrm{ml} \mathrm{min}^{-1}$, air at $100 \mathrm{ml} \mathrm{min}^{-1}$, and makeup gas (nitrogen) at $20 \mathrm{ml} \mathrm{min}^{-1}$.

\section{GC-MS analysis}

The GC-MS (mass spectral) analyses were performed using a Varian CP-3800 gas chromatograph, equipped with a Varian Saturn 2000 mass selective detector and a Saturn GC-MS workstation software (version 5.51). The column used was a Stabilwax-DA (Restek) fused silica column of $60 \mathrm{~m} \times 0.25 \mathrm{~mm}$ and $0.25 \mu \mathrm{m}$ phase thickness. The injector port was heated to $220^{\circ} \mathrm{C}$. The split vent was opened after $30 \mathrm{~s}$. The carrier gas was helium C-60 (Gasin), at a constant flow of $1 \mathrm{ml} \mathrm{min}^{-1}$. The oven temperature was programmed at $40^{\circ} \mathrm{C}(1 \mathrm{~min})$ to $220^{\circ} \mathrm{C}(30 \mathrm{~min})$ at $2{ }^{\circ} \mathrm{C} \mathrm{min}^{-1}$. All mass spectra were acquired in the electron impact (EI) mode. The ion trap detector was set as follows: the transfer line, manifold, and trap temperatures were, respectively, 230, 45 and $170^{\circ} \mathrm{C}$. The mass range was $m / z=33-350$, with a scan rate of 6 scans s$^{-1}$. The emission current was $50 \mu \mathrm{A}$, and the electron multiplier was set in relative mode to autotune procedure. The maximum ionization time was $25,000 \mu \mathrm{s}$, with an ionization storage level of $m / z=35$. The injection volume was $1 \mu l$, and the analysis was performed in full scan mode. 

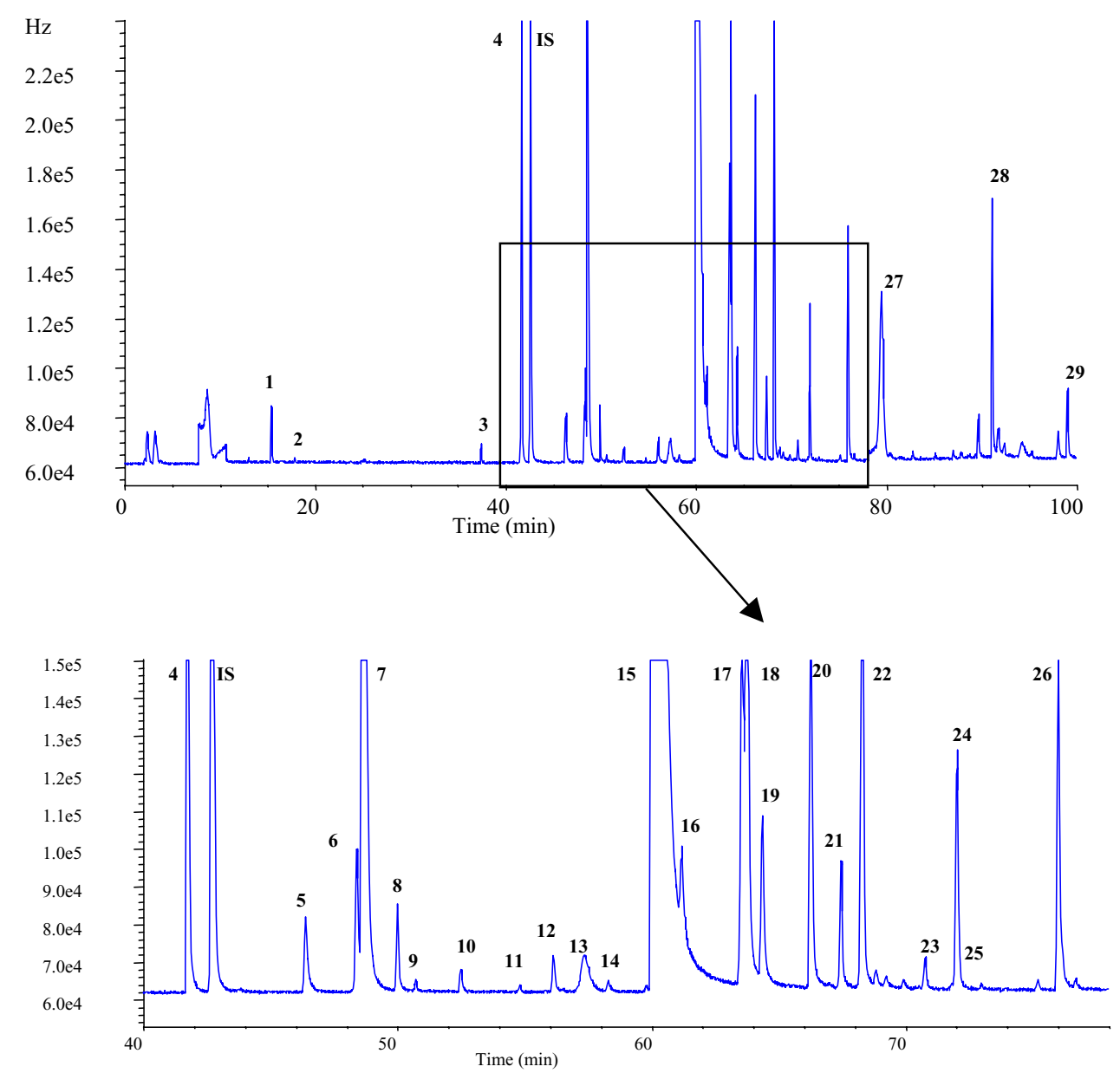

Fig. 1. Chromatogram of sulphur compounds in wine: (1) $S$-(methylthio)acetate; (2) $S$-(ethylthio)acetate; (3) peak $1^{\mathrm{A}}$; (4) peak $2^{\mathrm{A}}$; (5) 2-mercaptoethanol; (6) 2-(methylthio)ethanol; (7) 2-methyltetrahydrothiophen-3-one; (8) peak $3^{\mathrm{A}}$; (9) ethyl 3-(methylthio)propionate; (10) peak $4^{\mathrm{A}}$; (11) acetic acid-3-(methylthio)propyl ester; (12) 3-mercapto-1-propanol; (13) peak $5^{\mathrm{A}}$; (14) peak $6^{\mathrm{A}}$; (15) 3-(methylthio)-1-propanol; (16) peak 7А; (17) cis-2-methyltetrahydro-thiophen-3-ol; (18) 3-(ethylthio)-1-propanol; (19) peak $8^{\mathrm{A}}$; (20) trans-2-methyltetrahydro-thiophen-3-ol; (21)

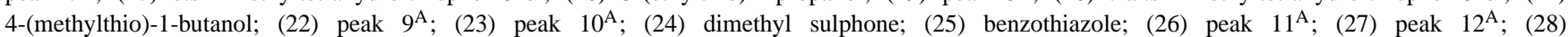
3-methylthiopropionic acid; (29) $N$-(3-(methylthio)propyl)-acetamide. ${ }^{\mathrm{A}}$ Unidentified substance, IS: internal standard, ethyl (methylthio)acetate.

\section{Sulphur compounds identification}

Sulphur compounds were identified by their retention time in a solution of a pure compound and by comparing mass spectra (SCAN mode) and retention times with those of standard references. When no standard reference was available, identification was carried out by comparing the Kovats indices and the mass spectra in the NIST 98 MS library database or in the literature. However, some sulphur compounds have not yet been identified.

\section{Study of recovery, repeatability and linearity}

Recovery was evaluated by addition of sulphur compounds to wines. Samples were submitted to four successive extractions with dichloromethane; after concentration, each organic phase was injected into the GC-FPD; for each sulphur compound the percentage recovery was determined by dividing the sum of the peak areas obtained from the first two extracts by the total peak area obtained for all extracts.

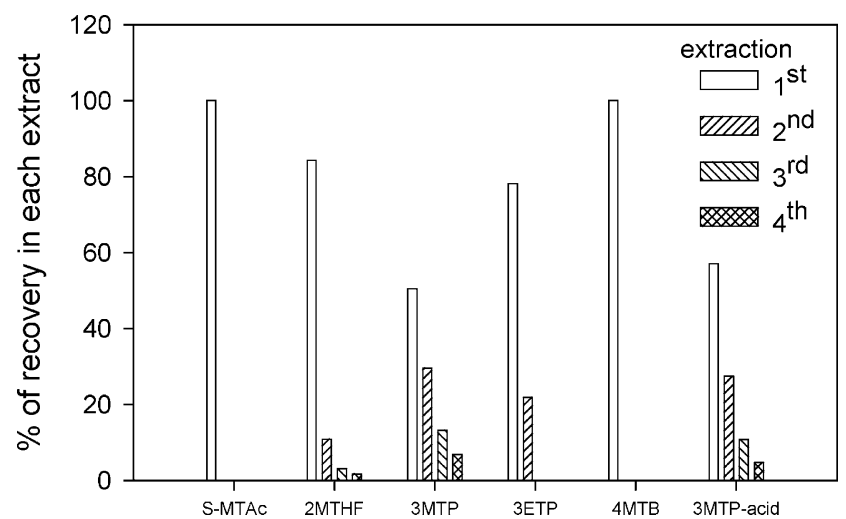

Fig. 2. Percentage recovery of $S$-(methylthio)acetate (S-MTAc, 12.3 $\mu \mathrm{gl}^{-1}$ ), 2-methyltetrahydrothiophen-3-one (2MTHF, $50.3 \mu \mathrm{gl}^{-1}$ ), 3-(methylthio)-1-propanol (3MTP, $\left.1080 \mu \mathrm{g} 1^{-1}\right)$, 3-(ethylthio)-1-propanol (3ETP, $\left.22.8 \mu \mathrm{gl}^{-1}\right)$, 4-(methylthio)-1-butanol (4MTB, $39.8 \mu \mathrm{gl}^{-1}$ ) and 3-methylthiopropionic acid (3MTP-acid, $756 \mu \mathrm{g}^{-1}$ ) in four successive extracts of a wine sample. 
Table 1

Recovery of sulphur compounds from red, white and Port wines

\begin{tabular}{|c|c|c|c|c|c|}
\hline \multirow[t]{2}{*}{ Sulphur compound } & \multirow[t]{2}{*}{ Range of content $\left(\mu g 1^{-1}\right)$} & \multicolumn{4}{|c|}{ Recovery (\%) } \\
\hline & & Minimum & Maximum & Mean & S.D. \\
\hline$S$-(Methylthio)acetate & $2.0-25.5$ & 100 & 100 & 100 & 0 \\
\hline$S$-(Ethylthio)acetate & $3.5-11.8$ & 100 & 100 & 100 & 0 \\
\hline 2-Mercaptoethanol & $21-210$ & 86.0 & 100 & 97.2 & 6.3 \\
\hline 2-(Methylthio)ethanol & $3.4-41$ & 87.1 & 100 & 96.8 & 6.5 \\
\hline 2-Methyltetrahydrothiophen-3-one & $26.3-87.7$ & 85.5 & 100 & 95 & 4.8 \\
\hline Ethyl-3-(methylthio)propionate & $5.1-16.9$ & 99.7 & 100 & 100 & 0.1 \\
\hline 3-Mercapto-1-propanol & $6.1-20.4$ & 64.0 & 88.5 & 73.8 & 11 \\
\hline 3-(Methylthio)-1-propanol & $448-2050$ & 79.4 & 96.4 & 86.1 & 7.3 \\
\hline 3-(Ethylthio)-1-propanol & $11.6-38.8$ & 94.0 & 100 & 97.5 & 2.3 \\
\hline 4-(Methylthio)-1-butanol & $28.9-96.2$ & 100 & 100 & 100 & 0 \\
\hline Dimethyl sulphone & $8.0-26.6$ & 53.1 & 69.6 & 60.3 & 7.6 \\
\hline Benzothiazole & $6.6-22.1$ & 100 & 100 & 100 & 0 \\
\hline 3-Methylthiopropionic acid & $499-1663$ & 61.7 & 92.2 & 79.7 & 12.3 \\
\hline
\end{tabular}

S.D.: standard deviation.

The mean values and standard deviations for all compounds were calculated.

The repeatability of the method was assessed from 10 analyses of the same wine, with or without addition of known quantities of sulphur compounds. The mean values, standard deviations and coefficients of variation for all compounds were calculated.

For each compound, a non-linear response of the FPD was obtained. The calibration graphs were obtained by analysing hydroalcoholic solutions of water/ethanol (12\% $(\mathrm{v} / \mathrm{v}))$ with different quantities of each sulphur compound, supplemented with $4 \mathrm{~g} \mathrm{l}^{-1}$ of tartaric acid and brought to $\mathrm{pH}$ 3.5 with $\mathrm{NaOH}$. The concentrations in wines of commercially available sulphur compounds were expressed as micrograms per litre. For unknown compounds and for those whose reference standards were not available, the amounts were expressed as the ratio of peak area $\times 10^{3} /$ peak area of the internal standard.

\section{Statistical methods}

An analysis of variance (ANOVA), using the $\operatorname{Excel}^{\mathrm{TM}}$ software from Windows 95 version 7.0, was applied to the experimental data; the results were considered significant if the associated $P$-value was $<0.05$.

\section{Results and discussion}

The principle of the method is the liquid-liquid extraction of the sulphur compound by a solvent, which is partially evaporated, and analysis of the concentrated extract by GC-FPD. The method was applied to red, white and Port wines.

The first step in this study was to compare various extraction solvents, ethyl acetate, diethyl ether, hexane, pentane, diethyl ether/hexane (50:50 (v/v)) and dichloromethane. The

Table 2

Repeatability and limits of detection of the method

\begin{tabular}{|c|c|c|c|c|}
\hline \multirow[t]{2}{*}{ Sulphur compound } & \multicolumn{3}{|l|}{ Repeatability } & \multirow[t]{2}{*}{ Limit of detection $\left(\mu g 1^{-1}\right)$} \\
\hline & Mean $\left(\mu g l^{-1}\right)$ & S.D. & $\mathrm{CV}(\%)$ & \\
\hline$S$-(Methylthio)acetate & 6.5 & 0.2 & 3 & 1.6 \\
\hline$S$-(Ethylthio)acetate & 5.1 & 0.4 & 8 & 1.8 \\
\hline 2-Mercaptoethanol & 64.4 & 5.2 & 8 & 8.6 \\
\hline 2-(Methylthio)ethanol & 3.6 & 0.4 & 12 & 1.5 \\
\hline 2-Methyltetrahydrothiophen-3-one & 52.4 & 4.9 & 9 & 4.9 \\
\hline Ethyl-3-(methylthio)propionate & 24.9 & 2.6 & 10 & 1.9 \\
\hline 3-Mercapto-1-propanol & 5.3 & 0.5 & 9 & 1.8 \\
\hline 3-(Methylthio)-1-propanol & 710 & 73 & 10 & 6.4 \\
\hline 3-(Ethylthio)-1-propanol & 16.4 & 1.4 & 8 & 2.5 \\
\hline 4-(Methylthio)-1-butanol & 5.6 & 0.6 & 11 & 4.9 \\
\hline Dimethyl sulphone & 129 & 18 & 14 & 9.8 \\
\hline Benzothiazole & 8.94 & 0.4 & 5 & 2.0 \\
\hline 3-Methylthiopropionic acid & 294 & 55 & 19 & 300 \\
\hline
\end{tabular}

S.D.: standard deviation, CV: coefficient of variation. 

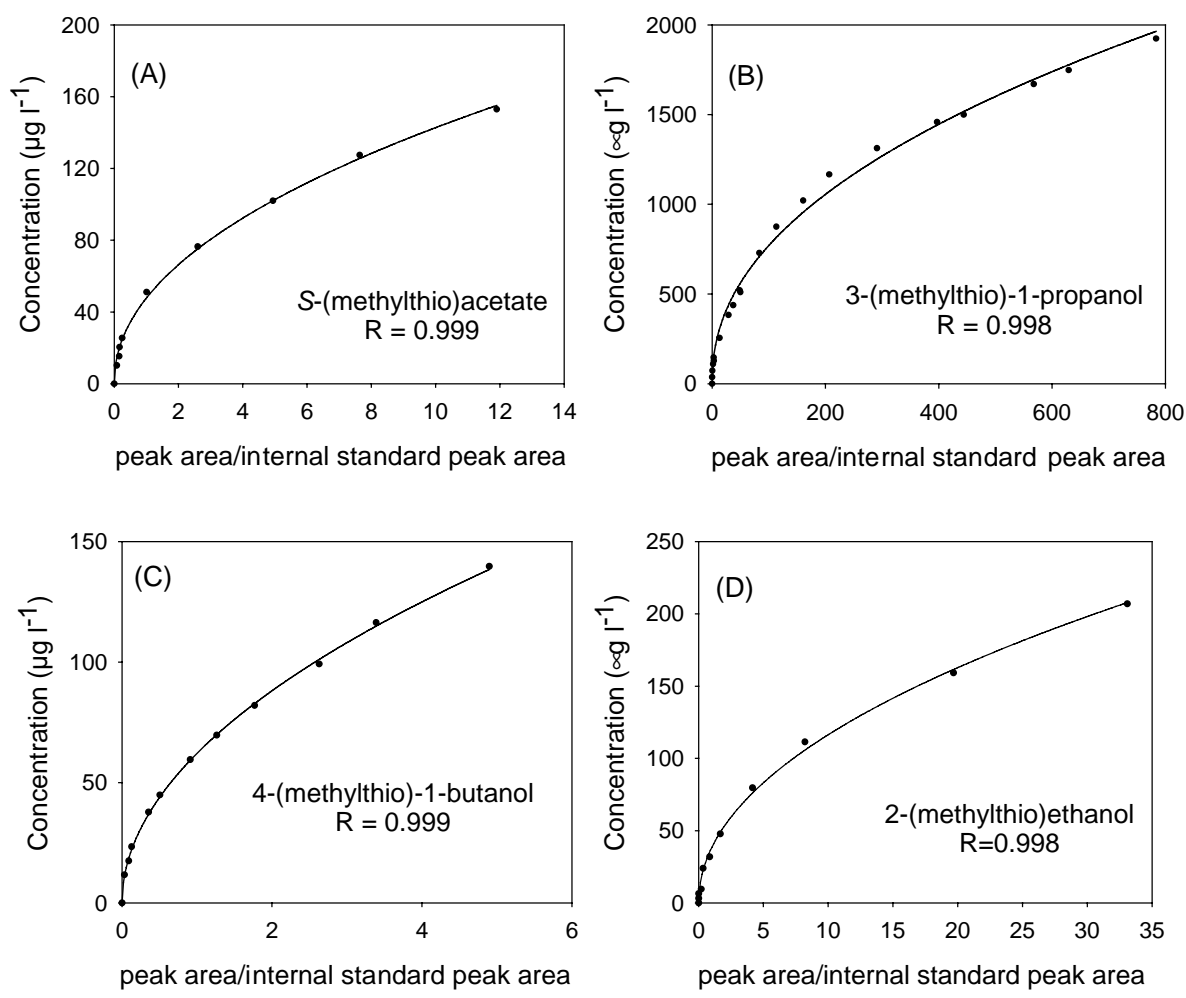

Fig. 3. Calibration graphs: (A) S-(methylthio)acetate; (B) 3-(methylthio)-1-propanol; (C) 4-(methylthio)-1-butanol and (D) 2-(methylthio)ethanol.

medium polarity solvent dichloromethane was chosen for further study because it recovered the largest amounts of sulphur compounds and resulted in the highest number of detected peaks. Good results were also obtained with ethyl acetate, but faults in repeatability tests were observed (data not shown).

The validation of the method was assessed by evaluation of the recovery of known quantities of substances, the determination of repeatability, the determination of limits of detection and the calibrations graphs.

Results from four successive dichloromethane extractions of some sulphur compounds of a white wine sample are presented in Fig. 2. According to the recovery values obtained, it was decided to perform two extractions with dichloromethane. The recovery percentages of sulphur compounds added to different wines (red, white and Port wines) at several concentrations are presented in Table 1. The results show that the sulphur compounds analysed presented a mean recovery $>90 \%$, except for 3-mercapto-1-propanol (73.8\%), 3-(methylthio)-1-propanol (86.1\%), dimethyl sulphone $(60.3 \%)$ and 3-methylthiopropionic acid (79.7\%). From the ANOVA test, it was possible to conclude that the percentage recoveries were not significantly different concerning the type of wine and the concentration of sulphur compound.

The mean values, standard deviations (S.D.s) and coefficient of variation $(\mathrm{CV})$ of 10 analyses of the same wine, with or without the addition of known quantities of sulphur compounds, are presented in Table 2. CV values were between 3 and 19\%, and for most sulphur compounds were $<10 \%$.

The limit of detection was considered to be the minimum concentration of compound for which detection was observed. As presented in Table 2, the limits of detection were $<6.4 \mu \mathrm{gl}^{-1}$, except for 2-mercaptoethanol $\left(8.6 \mu \mathrm{gl}^{-1}\right)$, dimethyl sulphone $\left(9.8 \mu \mathrm{gl}^{-1}\right)$ and 3-methylthiopropionic acid $\left(300 \mu \mathrm{gl}^{-1}\right)$. However, concerning the determination of defective aroma in wines, dimethyl sulphone is odourless and 2-mercaptoethanol has an olfactory perception threshold of $0.13-10 \mathrm{mg}^{-1}$ in wines $[5,8,9]$; consequently, determination can be performed using the method described. An olfactory perception threshold $<140 \mu \mathrm{g} 1^{-1}$ in wines was reported for 3-methylthiopropionic acid [5]; in this case the method only allows the quantification of this compound at concentrations higher than its olfactory perception threshold.

Examples of the non-linear response of the FPD to sulphur compounds are presented in Fig. 3; calibrations graphs were fitted by power functions. For all sulphur compounds studied the correlation coefficients were $>0.995$.

The analysis of red and white wines (Table 3) showed that concentrations of sulphur compounds were in agreement with those presented in the literature $[2,15]$. The highest concentrations were observed for 3-(methylthio)-1-propanol, 2-methyltetrahydrothiophen-3-one, 4-(methylthio)-1butanol, dimethyl sulphone, 3-methylthiopropionic acid and 
Table 3

Range of content of sulphur compounds in red, white and Port wines

\begin{tabular}{|c|c|c|c|c|}
\hline \multirow[t]{3}{*}{ Sulphur compound } & \multicolumn{4}{|l|}{ Content $\left(\mu g \mathrm{l}^{-1}\right)$} \\
\hline & \multirow[t]{2}{*}{ Red wines $(n=14)$} & \multirow[t]{2}{*}{ White wines $(n=12)$} & \multicolumn{2}{|l|}{ Port wines } \\
\hline & & & Old $(n=18)$ & Young $(n=18)$ \\
\hline$S$-(Methylthio)acetate & nd-19.5 & $1.8-8.8$ & nd & nd -4.82 \\
\hline$S$-(Ethylthio)acetate & nd & nd-3.9 & nd & nd-3.41 \\
\hline 2-Mercaptoethanol & nd-10.7 & $13.2-72.6$ & nd & nd-44.1 \\
\hline 2-(Methylthio)ethanol & $28.9-69.2$ & $6.3-11.6$ & nd & $13.9-50.4$ \\
\hline 2-Methyltetrahydrothiophen-3-one & $40.8-93.4$ & $47.8-185$ & nd & $48.7-214$ \\
\hline Ethyl-3-(methylthio)propionate & nd-8.0 & $2.1-3.2$ & nd & nd-7.6 \\
\hline Acetic acid-3-(methylthio)propyl ester ${ }^{\mathrm{a}}$ & nd-2.7 & $1.1-5.6$ & nd & nd-12.1 \\
\hline 3-Mercapto-1-propanol & nd-9.6 & $9.7-31.9$ & nd & nd-96.5 \\
\hline 3-(Methylthio)-1-propanol & $459-1137$ & $349-500$ & $8.7-53.7$ & $317-1851$ \\
\hline cis-2-Methyltetrahydrothiophen-3-ol ${ }^{\mathrm{a}}$ & $3.7-104$ & $6.9-321$ & nd & nd-140 \\
\hline 3-(Ethylthio)-1-propanol & $8.3-61.1$ & $9.6-31.7$ & nd-24.8 & $8.1-51.1$ \\
\hline trans-2-Methyltetrahydrothiophen-3-ol ${ }^{\mathrm{a}}$ & $2.1-120$ & $12.4-303$ & nd & $6.0-55.0$ \\
\hline 4-(Methylthio)-1-butanol & $19.5-40.2$ & $9.9-25.9$ & nd & $8.13-40.0$ \\
\hline Dimethyl sulphone & $11.8-45.9$ & $12.4-42.6$ & nd-23.4 & $19.3-74.2$ \\
\hline Benzothiazole & nd-8.9 & nd-32.7 & nd-12.0 & nd-27.3 \\
\hline 3-Methylthiopropionic acid & $317-379$ & nd -453 & nd-454 & nd -428 \\
\hline$N$-3-(Methylthiopropyl)acetamide ${ }^{\mathrm{a}}$ & nd-191 & $22.1-399$ & nd & nd-833 \\
\hline
\end{tabular}

nd: not detected.

a Peak area $\times 10^{3} /$ peak area of internal standard.

3-(ethylthio)-1-propanol in red and white wines. The analysis of sulphur compounds in young and old Port wines (Table 3) showed that old Port wines had fewer sulphur compounds and these were at lower levels than in young Port wines. This fact has been proved to be associated to aging parameters, such as dissolved $\mathrm{O}_{2}, \mathrm{pH}$ and temperature [16].

\section{Conclusions}

The presented method for quantification of heavy sulphur compounds is based on a GC-FPD analysis of samples obtained from liquid-liquid extraction with dichloromethane. This method allows a good recovery of 29 sulphur compounds (identified and unidentified) in wines, and an easy and rapid determination, with high sensitivity. The limits of detection were $<6.4 \mu \mathrm{gl}^{-1}$, except for 2-mercaptoethanol $\left(8.6 \mu \mathrm{g}^{-1}\right)$, dimethyl sulphone $\left(9.8 \mu \mathrm{g}^{-1}\right)$ and 3-methylthiopropionic acid $\left(300 \mu \mathrm{g} \mathrm{l}^{-1}\right)$. The method also allowed the separation of sulphur compounds across a wide range of boiling points and polarities. Moreover, the equipment described used an automatic injection system, which allows optimisation of human resources.

Concentrations of sulphur compounds found in red and white wines were in agreement with those presented in the literature. As expected, old Port wines had a lower content of sulphur compounds than young Port wines. Further research will allow the identification of sulphur compounds in wines related to organoleptic quality or off- flavours, as well as the understanding of their biosynthesis mechanisms.

\section{Acknowledgements}

The authors gratefully acknowledge the financial support from FCT, FSE (III Quadro Comunitário de Apoio) and PAMAF (INIA, Project 2025).

\section{References}

[1] P. Ribérau-Gayon, Y. Glories, A. Manjean, D. Dubourdieu, The chemistry of wine stabilization and treatments, in: Handbook of Enology, vol. 2, Wiley, Chichester, 1999.

[2] A. Anocibar Beloqui, A. Bertrand, Ital. J. Food Sci. 93 (1995) 279.

[3] P. Chatonnet, V. Lavigne, J.N. Boidron, D. Dubourdieu, Sci. Aliment 12 (1992) 513.

[4] D. Rauhut, W. Sponholz, in: T. Henick-Kling (Ed.), Proceedings of the 7th Australian Wine Industry Technical Conference, Adelaide, 1990, p. 196

[5] M. Mestres, O. Busto, J. Guasch, J. Chromatogr. A 881 (2000) 569

[6] A.B. Majcenovic, R. Schneider, J.P. Lepoutre, V. Lempereur, R. Baumes, J. Agric. Food Chem. 50 (2002) 6653.

[7] D. Rauhut, Production of sulphur compounds, in: G. Fleet (Ed.), Wine Microbiology and Biotechnology, Harwood Academic Publishers, Chur, Switzerland, 1993, p. 183.

[8] V. Lavigne, Recherches sur les composés soufrés volatils formés par la levure au cours de la vinification et l'élevage des vins blancs sec, Ph.D. thesis, University of Bordeaux II, Bordeaux, France, 1996.

[9] A. Anocibar Beloqui, Contribution a l'étude des composés soufrés volatiles des vins rouges, Ph.D thesis, University of Bordeaux II, Bordeaux, France, 1998. 
[10] A. Rapp, M. Günter, J. Almy, Am. J. Enol. Vitic. 36 (1985) 219.

[11] S.J. de Mora, P. Lee, D. Shooter, R. Eschenbruch, Am. J. Enol. Vitic. 44 (1993) 327.

[12] V. Bellavia, M. Natangelo, R. Fanelli, D. Rotilio, J. Agric. Food Chem. 48 (1993) 327.
[13] M. Mestres, O. Busto, J. Guasch, J. Chromatogr. A 945 (2002) 211.

[14] P.G. Hill, R.M. Smith, J. Chromatogr. A 872 (2000) 872.

[15] S. Karagiannis, P. Lanaridis, Am. J. Enol. Vitic. 50 (1999) 334.

[16] A. Ferreira, P. Rodrigues, T. Hogg, P. Guedes de Pinho, J. Agric. Food Chem. 51 (2003) 727. 